\title{
LA ONTOLOGÍA DE LA IMAGEN HÍBRIDA: ACTUALIZACIÓN DE LAS PREMISAS ONTOLÓGICAS EN LA TEORÍA DE ANDRÉ BAZIN
}

\section{THE ONTOLOGY OF THE HYBRID IMAGE: UPDATING THE ONTOLOGICAL BASIS OF ANDRÉ BAZIN'S FILM THEORY}

\author{
Lourdes Esqueda Verano \\ Universidad de Navarra, España \\ lesqueda@unav.es
}

\section{Resumen:}

Presenciamos una rápida evolución de la tecnología digital, hasta el punto en que resulta casi imposible para el espectador medio discernir entre imágenes de registro e imágenes generadas por ordenador. Esta alteración de los materiales que lo componen aviva nuevamente las incógnitas sobre la supuesta "muerte del cine". En este marco, se suele revisitar la teoría de André Bazin por el modo en que sus postulados sobre la ontología de la imagen fotográfica influyen en nuestra comprensión del cine. Este trabajo indaga en los principales argumentos esgrimidos por Bazin para sostener que el cine es un medio esencialmente realista y actualiza sus planteamientos mediante una comparación entre los tres materiales primarios que conforman la imagen cinematográfica actual: las imágenes de registro analógicas, las imágenes de registro digitales y las CGI. El objetivo de estas páginas es comprender en qué medida la hibridación ha transformado lo que llamamos cine a la luz de la mirada baziniana.

\begin{abstract}
:
We are witnessing a rapid evolution of digital technology, to the extent that nowadays it is almost impossible for the average spectator to discern between live action and ComputerGenerated Imagery. Such a development of its components brings about a theoretical problem: the socalled "death of cinema". André Bazin's theory has been constantly revisited because of his hypotheses on the ontology of the photographic image and its cinematographic implications. This paper aims to actualize Bazin's thought, through the link between film and its materials as well as his arguments regarding cinema as an essentially realist medium. To do so, we'll do a comparison between the three primary materials used to create pictures: optical images, both analogical and digital, and CGI. My final goal is to explore to what extent hybridization has transformed cinema from a Bazinian point of view.
\end{abstract}

Palabras clave:

André Bazin; teoría del cine; ontología de la imagen; cine híbrido; CGI; realismo.

Keywords:

André Bazin; Film Theory; Ontology of the image; Hybrid Cinema; CGI; Realism. 
Cómo citar: Esqueda Verano, L. (2018). La ontología de la imagen híbrida: actualización de las premisas ontológicas en la teoría de André Bazin. Fotocinema. Revista científica de cine y fotografía, $\mathrm{n}^{0}$ 16, pp. 243-264. Disponible: http://www.revistas.uma.es/index.php/fotocinema/ DOI: http://dx.doi.org/10.24310/Fotocinema.2017.voi16

\section{Introducción}

Desde el personaje de Gollum en El señor de los anillos: Las dos torres (Peter Jackson, The Lord of the Rings: The Two Towers, 2002), a los nativos de Pandora en Avatar (James Cameron, 2009) o al Gobernador Tarkin en Rogue One: Una historia de Star Wars (Gareth Edwards, Rogue One: A Star Wars Story, 2016), cada vez es más frecuente encontrarse con mundos y personajes creados por ordenador, que interactúan con imágenes grabadas de modo convencional. Este tipo de situaciones plantea una pregunta de corte ontológico, acerca de la naturaleza del cine en nuestra era digital. Nos enfrentamos a un medio que, en su origen, era una suerte de prolongación de la fotografía y que ahora se concibe muchas veces, como afirma Lev Manovich, como un subproducto de la pintura (1995, pp. 20-21).

Gabriel Giralt advierte también que la imagen cinematográfica actual tiende a levantar sospecha porque, incluso las representaciones realistas pueden no ser un complemento de la realidad objetiva, sino un sustituto hiperrealista (2017, p. 3). Esto se debe a la creciente hibridación de la imagen cinematográfica (Quintana, 2011, p. 192). Una mutación del cine en la que convive metraje de acción real con imágenes generadas por ordenador (CGI), lo que hace difícil discernir qué tipo de imagen contemplamos en cada momento. Nos encontramos en un tiempo en el que casi toda manipulación digital pasa desapercibida. E incluso cuando un filme se compone exclusivamente de imagen de registro, al encontrarse digitalizado, la materia prima de su imagen y la de las $C G I$ es la misma: el lenguaje binario.

El debate sobre el papel de la ontología de la imagen en el cine ha suscitado una recuperación del pensamiento de André Bazin, a quien en ocasiones se le ha 
posicionado de modo estereotipado en la trinchera contraria a la digitalización. Dicho posicionamiento contrasta con la actitud habitual de Bazin, que siempre abogó por las innovaciones técnicas del cine para explorar las posibilidades expresivas del medio (1952, pp. 4-5)1. Sin embargo, la popularidad de Bazin en estas reflexiones surge principalmente de su punto de partida, que es de corte ontológico-estético, distinguiéndose así de otras perspectivas, como la pragmática de Tom Gunning o la operativa de Jay Bolter y Richard Grusin, quienes abordan una serie de problemas aparejados a la convivencia entre lo analógico y lo digital mediante la remediación. En su capítulo dedicado al cine, Bolter y Grusin exponen la manera en que la animación se apropia de los movimientos de cámara utilizados con la imagen de acción real, el choque entre la plasticidad de lo digital y la concreción de la imagen de registro en el cine híbrido, así como el modo en que estas tecnologías afectan la transparencia y propician la hipermediación en el cine de atracciones (2000, pp. 146-158). Como se verá en este artículo, la teoría de André Bazin muestra que estas cuestiones operativas también encuentran una vía de solución mediante una pregunta previa, relativa a la ontología de las imágenes cinematográficas y el modo en que éstas definen la tendencia estética del séptimo arte.

El objetivo de este artículo es actualizar la teoría baziniana para rectificar la interpretación esencialista de sus textos y redescubrir la pertinencia de sus aportaciones en nuestra era digital. Siguiendo las premisas del pensamiento baziniano, en este artículo estudiaremos en primer lugar si el cine digital mantiene las mismas propiedades del analógico (ontología); y en segundo lugar si la hibridación de la imagen cinematográfica trastoca la tendencia natural del cine hacia el realismo (estética).

\section{Aproximación metodológica a la teoría de Bazin}

En la teoría baziniana, la ontología de la imagen fotográfica es el punto de partida fundamental para el realismo cinematográfico. El vínculo entre

\footnotetext{
${ }^{1}$ En André Bazin's New Media, Dudley Andrew recopila los textos bazinianos sobre diversas evoluciones técnicas en lo audiovisual. Si bien en esta colección no se incluyen aquellos textos sobre animación que tocan el asunto actual de la hibridación de un modo tangencial, en sus páginas es posible constatar el interés del crítico por el desarrollo tecnológico, incluyendo el $3 \mathrm{D}$ o las pantallas no cinematográficas.
} 
ontología y estética se ve especialmente subrayado cuando Bazin defiende la capacidad del cine para constituir una suerte de ventana hacia la realidad material mediante su imagen fotográfica, como un modo de acceso al mundo. En Ontología de la imagen fotográfica² Bazin propone que, gracias a la génesis de sus imágenes, la fotografía satisface el deseo psicológico del ser humano por el realismo y que lo logra mediante la preservación de la imagen del mundo (1966, p. 17). Esta premisa de corte ontológico tiende a impregnar sus textos sobre cine. Como cuando escribe que "el cine puede vaciarse de todas las realidades, excepto de una: la del espacio" (1966, p. 247). O la conocida metáfora del cine como asíntota de la realidad, donde, si bien distingue claramente entre realidad y cine, también establece entre ambos un vínculo innegable (1966, p. 25).

La de Bazin ha sido una de las teorías clásicas del cine más revisitadas desde que la digitalización incitó una crisis -más teórica que práctica- que obligó a repensar cuál es la esencia del cine digital. Siguiendo los planteamientos bazinianos, se pueden observar tres tendencias principales. Por un lado, David Rodowick y Manovich hablan de una muerte del fenómeno cinematográfico como tal. Otros, como Àngel Quintana, hablan de una mutación del cine. Por último, autores como Dudley Andrew sugieren que el cine convive con otro fenómeno que, si bien es audiovisual, no es cine (2010, p. xiii). Detrás de estas tres conclusiones encontramos una premisa común: la digitalización de la imagen trastoca la ontología del cine y, por tanto, cambia su esencia. Las tres posturas ofrecen perspectivas distintas sobre un único hecho innegable: el cine ya no es el mismo. Pero si el cambio es algo connatural al cine, por tratarse de un arte que descansa especialmente en la técnica, entonces existe la posibilidad de que la esencia del fenómeno siga siendo la misma. Como veremos, es posible identificar similitudes que, a pesar de las variaciones eidéticas entre los dos fenómenos -el analógico y el digital-, nos permiten ver con más claridad si este cambio afecta sustancialmente la ontología del medio y su esencia3, aquello que permanece a pesar de su desarrollo técnico.

\footnotetext{
2 De ahora en adelante, Ontologie.

3 La eidética refiere a la forma del objeto desprendido de lo contingente. Es decir, a su esencia. Hablar de variación eidética implica materialmente un cambio de esencia. Sin embargo, es
} 
Como se verá a lo largo del artículo, el mayor problema de la comprensión diacrónica del cine bajo la perspectiva baziniana radica en el establecimiento de una identidad entre lo analógico y lo propiamente cinematográfico. Esta idea será confrontada mediante una comparativa pormenorizada de la ontología de las materias primas del cine actual. Después se propondrá una breve reflexión sobre el lugar que las imágenes no-fotográficas pueden ocupar en el cine contemporáneo en el marco del realismo baziniano. Estas dos cuestiones atañen al fenómeno cinematográfico en sí, que es el aspecto nuclear del presente artículo, y permitirán relacionar ambos tipos de productos audiovisuales bajo la luz de sus variaciones eidéticas. Esto permitirá verificar si existe una esencia común para englobar lo analógico y lo digital bajo el fenómeno cine y, a su vez, ofrecer una actualización de la teoría de André Bazin.

\section{De la imagen analógica a la digital}

Al hablar de la ontología de la imagen cinematográfica hoy es necesario aproximarse a tres materiales distintos: la imagen fotográfica analógica, la imagen fotográfica digital y la imagen generada por ordenador. Por imagen fotográfica, sea analógica o digital, se entiende todo metraje de acción real o imagen de registro. La diferencia entre ambas radica en el soporte de almacenamiento (la analógica en celuloide; la digital en lenguaje binario). En Ontologie, Bazin parte de premisas sartreanas 4 para indagar sobre las potencialidades y peculiaridades de la imagen fotográfica, en cuanto materia prima del cine. El teórico francés defiende que el cine hereda de la fotografía sus principales propiedades, que se pueden agrupar en tres: su condición de huella, su esencial objetividad y la identidad ontológica entre modelo y fotografía. Dichas propiedades son fundamentales en la caracterización del medio y de su estética. Veamos detenidamente en qué consiste cada una.

posible enmarcar el uso que el medio hace de ambos materiales (CGI e imágenes de registro) dentro de un mismo fenómeno llamado cine. La ontología en cuestión aquí es la del cine, no de la fotografía.

4 Sartre comprende el signo en los términos en que lo expresa Umberto Eco, cuando dice que "signo es cualquier cosa que pueda considerarse como sustituto significante de cualquier otra cosa" (1977, p. 31). Para Sartre, las fotografías no sustituyen, sino que restituyen una realidad previa que participó de su origen (2006, p. 218). 


\subsection{La condición de huella}

En virtud de su génesis, la imagen fotográfica es una huella de la realidad por medio de la luz. Esta propiedad ha sido comprendida mayoritariamente en la academia desde la indexicalidad peirceana. Sin embargo, en los casi 2.600 artículos escritos por Bazin, dicho término no aparece ni una sola vez. La principal diferencia entre la huella baziniana y la indexicalidad de Peirce radica en que la segunda es un signo, algo que está por otra cosa; es decir, aparece como sustitución de algo. Por ello, comprender la imagen cinematográfica como signo implicaría que el cine representase los hechos registrados. En el pensamiento baziniano, en cambio, la fotografía participa "de la existencia del modelo como huella digital. Por ello se une realmente a la creación natural en lugar de sustituirla por otra” (1966, p. 19). Según Bazin, la fotografía no es un signo, pues no está por otra cosa, sino una manifestación, pues permite un acceso al aparecer de la realidad. La diferencia es, quizá, sutil, pero posee claras implicaciones ontológicas en lo que se refiere a la imagen y estética, así como en el realismo que se desprenda de las mismas.

También Mary Ann Doane defiende en un sentido similar que la fotografía no debería ser considerada como un índice ejemplar, porque

para Peirce, que definió el signo indexical, la fotografía no era en absoluto el ejemplo más importante. En su descripción, el índice se vacía de contenido; es un signo hueco. Designa algo sin describirlo; su función se limita a asegurar una existencia (2012, p. 338).

Bazin no comprende la imagen fotográfica como algo que designa la realidad pasada, sino como una huella presente. La lee pues, no sólo como prueba de su existencia pasada, sino como una inmortalización del momento en que se lleva a cabo el registro. Esto se debe a que el teórico francés analiza la ontología de la imagen fotográfica en sí y no la fotografía como objeto (imagen + soporte). En este punto, Bazin coincidiría con la lectura que Marta Torregrosa propone de Peirce, para quien "la función de los signos no se reduce a estar por los objetos, sean estos reales o imaginarios, sino a ser instrumentos de acceso y comprensión de lo real” (2010, p. 26). 
Atendiendo a su génesis, la imagen digital de registro también es una huella de luz. Es cierto que dicha huella carece de un soporte físico reconocible por el ojo humano, pero su condición de huella sigue siendo esencialmente la misma. Algunos filmes digitales, como Paterson (Jim Jarmusch, 2016), donde los efectos especiales (VFX) se reducen a una serie de versos que aparecen en pantalla, son de naturaleza híbrida y afectan al espectador igual que el cine analógico de los 50. En la práctica, la imagen de registro no necesariamente resulta sospechosa por ser digital. En la academia se ha apoyado esta postura utilizando terminología peirceana. Así, Tom Gunning subraya que las características indexicales de la imagen y la tecnología digital no son opuestas ni excluyentes (2004, p. 40). El registro en cámaras digitales no difiere del de sus homólogas analógicas en el sentido de que la máquina registra - sea en soporte celuloide o electrónico- una realidad profílmica. Philip Rosen secunda esta idea cuando dice que "lo digital no necesariamente excluye algo que resulta muy similar al evento profílmico de la indexicalidad” (2001, p. 307). Asimismo, la creencia de una imagen no-mediada por la tecnología en el soporte celuloide no deja de ser una simplificación del fenómeno porque, así como ocurre con la tecnología digital, lo analógico también requiere de un proceso -el reveladopara obtener la imagen. Recientemente, Giralt establece una distinción entre imagen creada (CGI,VFX) e imagen óptica (optical image), que abarca toda imagen de acción real, con independencia del soporte de registro (2017, p. 15).

En las CGI sí se trastoca la condición de huella de la imagen, porque su génesis es como en la pintura: no procede del registro, sino de la creatividad del artista. En la ideación de una imagen es posible contar con el mundo físico como referente y, a partir de éste, realizar una copia maleable. Así ocurre en Origen (Inception, Christopher Nolan, 2010), donde las calles de París se levantan en vertical. Las imágenes generadas también pueden ser diseños originales, sin un referente físico real, como el caso de Gollum en El señor de los anillos. En todo caso, la creación de las CGI siempre pasa por el filtro de la mente de su diseñador, diferenciándose del metraje de acción real, que encuentra su origen físico en la realidad misma. La fuente primaria de las CGI no es la realidad física, sino la materialización subjetiva de la noción de realidad o mundo posible concebida por una persona. 


\subsection{La objetividad fotográfica}

La segunda propiedad de la imagen fotográfica fue denominada por Bazin como "esencial objetividad" (1966, p. 18), que alude al modo mecánico en que la cámara registra lo profílmico. Es objetivo en el sentido de no-mediado por la subjetividad en la captura de la imagen, pues ésta se realiza de modo automático. Incluso las deformaciones de dichas imágenes -sea por medio de lentes especiales o filtros de color- se realizan mediante objetos que registran una realidad previa, de modo que el resultado no es, como tal, producto de la imaginación o visión humana, sino de un juego de objetos. Giralt incluye bajo la categoría de imagen óptica ambos tipos de imagen fotográfica -analógica y digital-porque "[el lente] permanece en contacto con la realidad aun cuando el cineasta no lo está" (Giralt, 2017, p. 15).

Con el paso del analógico al digital, se ha advertido una mayor facilidad para manipular la imagen, incluso durante la grabación, gracias a las aplicaciones y filtros incluidos en el dispositivo. Estas posibilidades levantan sus propias sospechas, pero cabe puntualizar dos cosas: que no se trata de un fenómeno nuevo, aunque quizá sí más frecuente; y que, pese a la manipulación, la imagen no dejaría de ser una huella -deformada- de la realidad, fruto del registro objetivo (realizado con un objeto) de la misma. Bazin advirtió la maleabilidad de la imagen y que el punto de vista del cineasta al colocar la cámara modifica el sentido de lo capturado; sin embargo, insistía en que el cine siempre sería objetivo en el sentido de que entre la realidad y la cosa media un objeto, que funciona de manera automática. Gracias a la fotografía, dijo Bazin, "por primera vez una imagen del mundo exterior se forma automáticamente sin intervención creadora por parte del hombre, según un determinismo riguroso" (1966, p. 18). Este punto es esencial para distinguir entre artes de registro y artes de diseño.

La herramienta que produce las CGI es esencialmente distinta. Los ordenadores poseen programas que permiten gran nivel de precisión, diversidad de texturas y fuentes de iluminación, sencillez en los retoques, la posibilidad de dar marcha atrás y simular leyes físicas, análogas a los movimientos naturales. Se trata de un proceso manual, con ayuda de la tecnología informática y en equipo. El automatismo u objetividad que le son propias a la fotografía no caben aquí, a 
pesar de que las imágenes alcancen una apariencia fotorrealista plena. Este punto es clave porque, como decía Bazin, "por muy hábil que sea el pintor [y podríamos decir también el diseñador], su obra se encuentra siempre bajo la hipoteca de una subjetivación inevitable” (1966, p. 16). Aquí cabe matizar que las CGI no siempre son completamente independientes de la realidad física, en el sentido de que para simular la naturaleza es necesaria una detenida observación previa de la misma y de su comportamiento. De ahí que las CGI alcancen un elevado nivel de realismo visual y se tornen indiscernibles de las imágenes ópticas, como ocurre en los filmes de Alejandro González Iñárritu El renacido (The Revenant, 2015) o Birdman (2014), y en Gravity (Alfonso Cuarón, 2013), donde Emmanuel Lubezki ha ganado el Óscar a mejor fotografía por su trabajo con imágenes híbridas.

\subsection{La transferencia de realidad a la fotografía}

La trascendencia de la objetividad fotográfica se ve con mayor claridad en lo que Bazin llama transferencia, y que constituye la tercera propiedad de la imagen fotográfica: la identidad ontológica. Bazin defiende que la realidad se transfiere, en cierto sentido, desde la cosa fotografiada hacia su representación fotográfica. Postula, incluso, que existe una cierta identidad ontológica entre ambas. Para comprender este aspecto de la fotografía, Daniel Morgan propone considerar literalmente la defensa baziniana de que la fotografía no se parece a la realidad, sino que, en cierto sentido, es la realidad misma (2006, pp. 448449). Se trata de una defensa compleja porque la realidad y su imagen fotográfica no pueden ser lo mismo. Siguiendo la propuesta de Jean-Paul Sartre, una fotografía de Pedro no es Pedro. Sin embargo, en el lenguaje coloquial al señalar la fotografía se dice “este es Pedro" (Sartre, 2006, p. 200). Desde esta perspectiva, al no constituir un signo, sino una huella visual de la realidad, no pensamos en dicha fotografía como una imagen de Pedro, sino como Pedro en un tiempo distinto.

Para Bazin, la imagen fotográfica no es un duplicado ni una semejanza: es lo real fuera del tiempo, la momificación atemporal de lo real. Así es como se hace posible la transferencia de la que habla Bazin. El concepto de transferencia presenta su propia problemática, pues una transferencia consiste en pasar o 
llevar algo desde un lugar a otro (Esqueda \& Cuevas, 2012, p. 7). Transferir algo implica, pues, (a) que el objeto transferido no puede estar simultáneamente en los dos sitios y (b) que lo transferido es igual a sí mismo en el punto de partida y el destino. De modo que, al hablar de transferencia de realidad de la cosa a su fotografía cabría interpretar que lo transferido es la apariencia del momento concreto de la cosa. Es decir, la cámara captura esa determinada apariencia que la realidad en cuestión tenía en el momento en que se realizó la fotografía. Según Stanley Cavell, la identidad ontológica entre la cosa y el modelo tiene un efecto concreto en el espectador que propicia la valoración de lo mostrado como realista (1979, pp. 130-155). Precisamente este es el efecto identificado por Bazin, quien habla de un reconocimiento (reconnoissance) del mundo, un concepto que apunta al rasgo distintivo de la representación cinematográfica porque el cine así comprendido no sólo representa el mundo, sino que lo presenta ante el espectador (1947a, p. 679).

Como las CGI son fruto de la simulación, no nos presentan ante una realidad profímica pasada y el proceso de transferencia es imposible. Sin embargo, el reconocimiento descrito por Cavell sí es posible porque el acto de re-conocer no se circunscribe a aquello que posee una apariencia material concreta, sino a la capacidad de identificar algo que se conoce. Incluso si lo simulado no es un espacio o un cuerpo real, como las calles de París en Origen, sino imágenes fantásticas, el sujeto es capaz de reconocer lo representado. Debido a las particularidades de su proceso creativo, el resultado de la generación de imágenes consiste en crear una apariencia -verosímil o no, posible o no, similar a un modelo real o no- que puede provenir de la imaginación del artista. La imaginación no es ajena a la experiencia humana. Los productos mentales, recuerdos, ensoñaciones y sueños carecen de materialidad, pero son igualmente constitutivos de la realidad en el sentido de que, incluso si las imágenes no se corresponden con la apariencia de un ente real, su ideación es posible gracias a lo previamente percibido por el sujeto en la realidad. Este es el principio de la copia de David Hume, quien comprende que nuestras ideas no son sino copias débiles de nuestras impresiones (T.1.1.1.7/4). Los pegasos tienen alas porque, aunque nunca se ha visto uno, la imagen caballo y la imagen alas sí han sido percibidas previamente. La mente las une, dando lugar al ser fantástico. Lo 
mismo ocurre con ciertos productos habituales de las CGI, como los dragones de apariencia tan distinta que encontramos en Pedro y el dragón (David Lowery, Pete's Dragon, 2016), un felpudo gato alado, o los lagartos voladores de los Nazgûl en El señor de los anillos. Aunque su naturaleza sea muy diferente, tanto los productos de la imaginación como las apariencias provenientes de la realidad, permiten reconocer lo representado, pues ambas son parte de la experiencia humana.

\section{El cine tras la hibridación}

Ante las posibilidades ilimitadas de manipulación y creación mediante CGI, tenemos la imagen óptica que en el cine híbrido se mezcla con las primeras, dando lugar a una realidad que cohabita con la imaginación en un mismo plano de existencia: la pantalla. Quintana llama a este fenómeno "cine híbrido" (2011, p. 192). Se habla de hibridación cuando dos elementos de distinta naturaleza se unen, dando por resultado un producto esencialmente distinto de ambos y que, sin embargo, mantiene similitudes y una relación de parentesco con dichos elementos. Efectivamente, en el cine actual se unen dos tipos de imagen con naturaleza distinta en un único producto. Como ya se ha dicho, es posible identificar algunas similitudes entre el producto resultante y sus dos materias primas, así como rastrear la línea de parentesco que las preceden.

Sin embargo, al tomar el término híbrido al pie de la letra, es necesario afrontar la cuestión sobre si este producto es esencialmente distinto de los dos que lo conforman. Quintana afirma que el cine "ha pasado de ser un sistema de reproducción de la realidad a convertirse en un sistema de representación" (2011, p. 192). Dentro de este planteamiento se debe considerar que la hibridación cinematográfica conoce de grados. Desde el metraje de acción real que se somete a diferentes procesos de postproducción digital, hasta los filmes compuestos casi completamente por CGI. Este último caso no es la norma, aunque sí resulta cada vez más habitual encontrarlo en determinados géneros, como en el cine de acción o el de fantasía y ciencia ficción. En cambio, géneros como el drama y la comedia tienden a dar más peso a la imagen de acción real que a los efectos especiales. En algunos casos, las CGI no tienen entidad 
suficiente como para hablar de un producto híbrido, en el sentido de que genéticamente no está compuesto a partes iguales por los dos elementos.

Pese a esta gradación del carácter híbrido del cine actual, la maleabilidad de la imagen digital ha suscitado en la academia una especulación generalizada sobre un posible cambio de fenómeno. En un texto titulado What is Digital Cinema? -un guiño evidente a la obra baziniana- Lev Manovich ha acuñado el término kino-brush en oposición al kino-eye (1995, pp. 20-21). Jenna Ng retoma el concepto kino-brush y sentencia que el cine ha dejado de ser un arte de registro, para convertirse en otro fenómeno más cercano a la pintura, pues las imágenes animadas que incorpora no poseen un vínculo existencial con la realidad (2007, p. 175).

Efectivamente, como observan Manovich y Jenna, la hibridación de la imagen cinematográfica no es un elemento inocuo en un arte que se ha basado primordialmente en el registro. Sin embargo, si miramos el cine desde la perspectiva baziniana, es decir, considerando el cine como un arte cuya técnica se encuentra en constante evolución, estos avances no acaban con la esencia del cine, así como no lo hizo el sonido, ni el color, ni el cambio de formato de las pantallas. Estos cambios o desarrollos se orientan a distintos objetivos, que responden a las necesidades y deseos creativos de cada época, pero sin que esto lleve a dejar de hablar de un mismo fenómeno.

También en la imagen híbrida es posible afirmar, en términos bazinianos, que el cine constituye una asíntota de la realidad, una línea quizá más errática, pendulante. El cine híbrido sigue conservando también la única realidad de la que no puede desprenderse: el espacio. Aunque en algunos casos se presenta un espacio real registrado y en otros un espacio imaginario, generado por ordenador. La inclusión de una nueva herramienta no acaba con este arte, sino que provee de nuevos métodos y amplía sus vías de exploración estética.

Ante la teoría de un Bazin entusiasta del desarrollo técnico, resulta paradójico que se tomen sus postulados sobre la ontología de la imagen fotográfica para desestimar el cine de soporte digital. La ontología de la imagen cinematográfica no puede prescindir del tiempo (duración), del montaje (elipsis, composición) o del cruce entre espacio, tiempo y montaje (el movimiento). Los planteamientos 
bazinianos llevan, efectivamente, a comprender el cine digital como una mutación del fenómeno cinematográfico, pero no necesariamente a hablar de una muerte del cine.

Un acercamiento baziniano al cine digital se podría formular de la siguiente forma: la esencia del cine no es una consecuencia inmediata de la ontología de sus imágenes ni depende de ésta; aunque como rasgo exclusivo de la fotografía y del cine, las artes de registro cuentan con un valor añadido del que carecen otros artes en lo relativo a la mostración del mundo. La digitalización no es la muerte del cine, sino la asimilación de una técnica más, que se suma al cúmulo de técnicas que se han incluido históricamente en su desarrollo como arte.

Contrario a algunas lecturas que posicionan a Bazin como un esencialista, el teórico francés no considera que la ontología de la imagen fotográfica sea la esencia del cine. Bazin la considera más bien como un factor decisivo que orienta al cine hacia una tendencia realista. Este realismo particular sí le es esencial -único o exclusivo- a las artes de registro. Es cierto que Bazin no escogió inintencionadamente Ontologie como texto de apertura a su compilación de textos, y que propone una distinción entre el cine y las demás artes por su posibilidad de ofrecer un realismo estético mediante la apariencia del mundo. En este postulado que vincula ontología y realismo es donde se tiende a reducir a Bazin al defensor de la imagen de registro y enemigo de lo digital. Por ello, a continuación, se ofrece una breve reflexión al respecto que, si bien no abarca el realismo cinematográfico en su integridad, ya que dicha labor excede los límites del presente artículo, sí indaga en las premisas de la relación ontología-tendencia estética realista y su posible aplicación al cine híbrido.

\section{Por un realismo híbrido}

El realismo es un término polisémico, máxime en cine, donde coexisten diversos enfoques de valoración del mismo. Bazin advierte que el fenómeno cinematográfico es más complejo de lo que parece, pues conjunta distintos sistemas de significación que habían estado separados en las artes que le precedían. Pensemos en el naturalismo pictórico, el modernismo literario, o en el retrato mortuorio. Debido a esta complejidad, Bazin advierte que fundar el 
realismo cinematográfico en términos de verosimilitud visual lleva a caer en la trampa del pseudorrealismo psicológico, que predomina en la generación de imágenes. Este realismo meramente visual o formal es análogo al hiperrealismo pictórico o escultórico, que se esfuerza por reproducir determinada apariencia con fidelidad cuasi-fotográfica, sin dejar rastro de su génesis subjetiva; son creaciones manuales y no de registro. Autores como Seung-Hoon Jeong defienden un realismo perceptual de las CGI pues si bien no son indexicales, sí pueden optar a un efecto-índice, gracias al fotorrealismo que alcanzan con las nuevas mejoras técnicas (2016, p. 99). Este argumento contradice la denuncia baziniana del pseudorealismo que se satisface con la ilusión de las formas. Sin embargo, autores como Giralt comprenden que, debido al minucioso detalle y la indiscernibilidad entre imágenes ópticas y CGI, en términos de representación, las imágenes de registro y las CGI son intercambiables, pues ambas suponen una mirada sobre una cierta realidad, que puede ser de contenido material (captado por el ojo) o humanista (captado con el intelecto). A diferencia de Seung-Hoon, Giralt advierte que el metraje de acción real cuenta con un ingrediente imposible de reproducir mediante la generación de imágenes: la autenticidad (2017, p. 16). Lo auténtico es clave para comprender el realismo estético baziniano, ya que, según Bazin, el verdadero realismo cinematográfico posee dos propiedades que le son exclusivas y, por tanto, esenciales como arte: la autenticidad de lo representado y el acceso a la significación concreta y esencial del mundo (1966, p. 16).

La autenticidad encuentra varias manifestaciones en el cine: a nivel ontológico, estilístico y poético. En los límites de este artículo, circunscrito al nivel ontológico, cabe decir que la autenticidad no puede simularse. La imagen óptica cinematográfica, que hereda las propiedades de la fotografía, es auténtica por esa transferencia de la realidad al celuloide, que la hace idéntica a sí misma. Es decir, idéntica a la realidad profílmica que la originó. La ontología de sus imágenes es lo que confiere al cine este tipo de realismo que le es esencial, en el sentido de "exclusivo", no de "imprescindible". Es necesario hacer este matiz, porque Bazin no considera que el cine sea realista per se; más bien, Bazin habla de un realismo esencialmente cinematográfico. Es decir, sólo el cine es capaz de presentar la imagen en movimiento del mundo. Dicho de otro modo, la 
autenticidad de la imagen cinematográfica -al ser una huella objetiva que transfiere la imagen de la realidad a un soporte- es una posibilidad exclusivamente cinematográfica.

Ahora bien, el objetivo de este artículo consiste en actualizar la comprensión baziniana de la ontología de la imagen cinematográfica. ¿Qué pasa con las CGI?, ¿no pueden ser éstas también cinematográficas y realistas? Una posible respuesta se encuentra, esta vez, en algunos textos bazinianos menos conocidos, como "Peut-on s'intéresser au cinéma?", donde critica que la animación se someta a las leyes físicas de la realidad5; o en su artículo sobre la edición de 1947 del Festival de Cannes, donde reseña Dumbo (Ben Sharpsteen, 1941) como lo mejor de Walt Disney, porque en la escena de los elefantes rosas se exploran las posibilidades y la plasticidad de la imagen animada, al representar un estado mental sin apariencia profílmica registrable y, sin embargo, experimentado subjetivamente por las personas (1947b).

Aunque las CGI no cuentan con la autenticidad de las imágenes de registro, sí son un medio idóneo para reproducir los estados de conciencia y, por tanto, un modo de acceso a las realidades subjetivas e inmateriales. Estas imágenes mentales carecen de un referente físico que pueda ser registrado y además tienen la peculiaridad de que su comportamiento transgrede las leyes de la física y de la razón. Este es el caso de lo onírico, lo fantástico y lo sobrenatural.

Antes de la era digital, diversos cineastas demostraron su capacidad para representar este tipo de realidades mediante la imagen óptica. Para ello, se recurrió principalmente a dos técnicas: la sugerencia mediante la elipsis, o la simulación mediante los movimientos de cámara, el uso de lentes especiales y los juegos del montaje. Dos ejemplos paradigmáticos de ellos son Diario de un cura rural (Journal d'un curé de campagne, Robert Bresson, 1951), donde se sugiere la acción de la Gracia de Dios, y Redes en el atardecer (Meshes of the Afternoon, Maya Deren, 1943), que representa el desarrollo subconsciente de las emociones. En ambos casos, se explora la significación esencial del mundo constitutiva, según Bazin, del realismo estético.

\footnotetext{
5 Bazin critica las obras naturalistas de Disney por "atar" sus dibujos a las constricciones de la realidad física, cuando la imagen animada es tan plástica que lo propio es experimentar con esa libertad (1956, p. 5).
} 
Más allá de que las imágenes simuladas carezcan de la autenticidad de las imágenes de registro, conviene advertir la complejidad ética y estética que surge de la hibridación de ambas, trastocando potencialmente la ontología del medio. Esta problemática se hace explícita en las entregas más recientes de La guerra de las galaxias, donde la simulación afecta la transparencia del filme e incluso suscita preguntas sobre los límites éticos de su uso. Alexi Sargeant ofrece una reflexión a propósito de Rogue One, donde se resucita digitalmente a Peter Cushing, fallecido en 1994, para encarnar nuevamente al Gobernador Tarkin. Este spin-off, además de plantear un debate sobre la legitimidad de la simulación de actores, se instaura como una muestra del virtuosismo técnico que se ha alcanzado en los últimos años. Sargeant destaca la peculiaridad de este ejemplo pues, además de sus implicaciones negativas desde el punto de vista ético, consigue un efecto negativo a nivel estético, porque "mediante las actuaciones post-humanas, el cine se aleja cada vez más de ser un arte para acercarse a un producto" (Sargeant, 2017). La simulación de actores fallecidos, como Cushing en Rogue One, o incluso la sospecha de que pudiera ocurrir, como en el caso de Carrie Fisher en El último Jedi (Rian Johnson, Star Wars: The Last Jedi, 2017), propicia un tipo de reconocimiento distinto al de la imagen de registro, ya que el espectador sale de la trama para preguntarse sobre el modo en que esa imagen fue generada. Aunque un actor fallecido sea un referente real y aparezca ante nosotros como si estuviera vivo, no puede ser valorado como auténtico, porque sabemos que ya no está en este mundo. Estos casos producen, diría Bazin, una contradicción ontológica o una mentira estética, que consiste en presentar como reales acciones imposibles o que carecen de sentido y tergiversan el sentido de la realidad (1966, p. 55). El pacto de lectura que permite al espectador reconocer un "auténtico" dragón lógicamente generado por ordenador - no suple la falta de vida de un actor que sólo puede actuar en vida.

Bazin menciona un segundo elemento para la consecución de este realismo estético: que posibilite el acceso a la significación concreta y esencial del mundo. En este punto caben, principalmente, dos interpretaciones desde el punto de vista de la ontología de la imagen. Primero, que la significación concreta del mundo se refiere a la imagen concreta de los seres y de las cosas 
registrados por la cámara. Como dijo Bazin, "las virtualidades estéticas de la fotografía residen en su poder de revelarnos lo real" (1966, p. 19). O, en un sentido más amplio, en la mostración de esa significación esencial mediante lo concreto; comprendiendo por concreto todo aquello que puede ser percibido por los cinco sentidos. En esta interpretación, las CGI también representan determinada concreción, aunque carezcan de la autenticidad que le es exclusiva a las artes de registro. Cabe mencionar que la concreción no necesariamente busca el efecto-índice como propone Seung-Hoon, porque no requiere de una apariencia fotorrealista, sino tan sólo de una existencia visual, que podría ser tan caricaturizada como las animaciones presentes en El mundo (Shijie, Jia Zhangke, 2004). Por el contrario, como ocurre en el caso del Gobernador Tarkin, una imagen fotorrealista puede jugar en contra de ese realismo buscado, pese a ser visualmente indiscernible respecto del actor original. Valga con este contraejemplo para sostener que, pese al principio general de que las CGI no constituyen un obstáculo per se para el realismo de una obra, deberá evaluarse la adecuación de las imágenes en cada película concreta.

Se ha dicho más arriba que dos rasgos propios del cine son la autenticidad y la posibilidad de acceder al mundo en su discurrir temporal. Se entiende que el primero, la autenticidad, es exclusiva de las artes de registro; pero la segunda, el acceso al mundo en su temporalidad, no necesariamente dejaría fuera las CGI. Considerando que el cine actual es un arte híbrido -o de tendencia híbrida- y las premisas ya expuestas de la teoría baziniana, podríamos decir que las $C G I$ suponen un medio ideal, dada su plasticidad, para la representación temporal de lo que Bazin llamó realidades espirituales. Como explica Bazin, antes de la invención de la fotografía, la pintura estaba

dividida entre dos aspiraciones: una propiamente estética -la expresión de realidades espirituales donde el modelo queda trascendido por el simbolismo de las formas- y otra que no es más que un deseo totalmente psicológico de reemplazar el mundo exterior por su doble (1966, p. 15).

En este sentido, las $C G I$ son una vía para representar lo inmaterial mediante imágenes concretas. La plasticidad de estas imágenes no es una amenaza contra el cine, sino una ventaja, una herramienta expresiva que el cine puede incorporar. Como defiende Kristen Daly, en el cine híbrido es posible alcanzar el 
ideal de la caméra-stylo defendido por Asturc y Bazin, gracias a la incorporación de nuevas técnicas para crear representaciones a partir de una imagen de registro (2009). Recuperemos el verdadero sentido que el realismo cinematográfico tenía para Bazin, quien dijo:

El buen cine es, desde luego, de una manera u otra más realista que el malo. Pero esa condición no es en absoluto suficiente, pues reflejar mejor lo real no interesa sino para hacer que signifique más. En esta paradoja reside el progreso del cine (1999, p. 80).

Si parte de esta paradoja implica una hibridación en la misma ontología de la imagen, el realismo cinematográfico no está en peligro, sino tan sólo en el siguiente paso de su evolución natural como arte técnico. En lo tocante a la ontología de la imagen híbrida, un realismo esencialmente cinematográfico sigue siendo posible. La cuestión sobre si obras concretas como Origen o La guerra de las galaxias son realistas como un todo, requerirá un análisis sobre el uso concreto de las herramientas del lenguaje y sobre el modo en que abordan determinadas realidades desde un punto de vista narrativo. La ontología de la imagen cinematográfica posibilita un determinado realismo, pero, como advirtió Bazin hace ya más de medio siglo, el cine también es un lenguaje y un punto de vista o afirmación sobre la realidad. En ese sentido, para valorar si el resultado de ciertas películas es realista, la ontología de su imagen es tan sólo un primer paso.

\section{Conclusiones}

Una vez cuestionadas las premisas ontológicas de André Bazin a la luz del cine híbrido, se ha constatado que, si bien el fenómeno en cuestión no desaparece, sí se ve modificado tanto en su ontología como en el tipo de realismo al que aspira. La génesis de las CGI pasa siempre por el filtro de la subjetividad del artista y, por tanto, no son una huella de luz que se impresione en un soporte, ni se generan de forma automática (objetiva). Por ende, las CGI no presentan una identidad ontológica con la realidad, como sí ocurre en las imágenes ópticas.

Estas peculiaridades de las CGI no restan realismo perceptivo a la imagen, pero sí que les quita un componente fundamental de la imagen de registro: la 
autenticidad de lo representado. Sin embargo, hay dos consideraciones que pueden ayudar a incluir las CGI en el cine sin necesariamente atentar contra su realismo. La primera tiene que ver con el grado de manipulación y la cuestión sobre la necesidad o no de acudir a la generación de imágenes para representar determinadas cosas, paisajes o seres. Esta valoración, como se ha dicho, dependerá de cada caso concreto, donde es posible comprobar el grado de hibridación de las imágenes y valorar la legitimidad o no de acudir a las CGI.

El segundo aspecto considerado en este trabajo tiene que ver con las potencialidades plásticas de las imágenes generadas por ordenador y con cómo el cine puede incluirlas y mezclarlas con imágenes de registro para lograr una más completa representación de la realidad. En este artículo hemos hablado de cómo la realidad física se percibe con los cinco sentidos y la realidad inmaterial, con el intelecto. Si el cine es, para Bazin, un modo de acceso al mundo mediante lo concreto, las $C G I$ contribuyen a este fin, pues son un medio idóneo para dar visibilidad a lo inmaterial, a lo que es inaccesible mediante los ojos: lo sobrenatural, lo onírico, lo fantástico.

Así, puede aventurarse que para Bazin las imágenes generadas por ordenador podrían constituir un aliado en la representación del mundo. El hallazgo en este campo consistiría, precisamente, en la posibilidad de una imagen híbrida que cumpliese lo que Bazin consideró como el verdadero realismo -o realismo estético-, que se orienta hacia la representación de realidades espirituales. El cine híbrido actual (igual que la pintura mencionada por Bazin) no se satisface con la semejanza de las formas, sino que busca la significación concreta y esencial del mundo. En este sentido, el cine se acerca a la pintura, por las contingencias de un arte fundado en la técnica, pero no necesariamente ha perdido su esencia que consiste, según Bazin, en revelar lo real.

\section{Referencias bibliográficas}

Andrew, D. (2010). What Cinema Is! Massachusetts: Wiley-Blackwell.

Bazin, A. (2014). André Bazin's New Media. D. Andrew (trad. \& ed.). Berkeley: University of California Press. 
Bazin, A. (1999). Renoir francés. En F. Truffaut (ed.), Jean Renoir. Períodos, filmes y documentos (pp. 73-84). Barcelona: Paidós.

Bazin, A. (1966). ¿Qué es el cine? Madrid: Rialp.

Bazin, A. (1956). Bonjour cinéma d'animation. RCT, 333, 4-5 y 41.

Bazin, A. (1953). Le langage de notre temps. En J. Chevallier y M. Egly (ed.), Regards neufs sur le cinéma (pp. 5-17). Paris: Le Seuil, collection Peuple et Culture.

Bazin, A. (1952). Un nouveau stade du cinéma en relief: Le relief en equations, $R C T, 131,4-5$.

Bazin, A. (1947a). Farrebique ou le paradoxe du réalisme. Esprit, 132, 676-680.

Bazin, A. (1947b). Au festival de Cannes Un grand film français: Les Maudits Le meilleur Walt Disney: Dumboo [sic]. Parisien Libéré, 932.

Bolter, J.D. \& Grusin, R. (2000). Remediation. Understanding New Media. Massachusetts: MIT Press.

Cavell, S. (2005). Cavell on Film. W. Rothman (ed.), Albany: State University of New York Press.

Cavell, S. (1979). The World Viewed. Massachusetts: Harvard University Press.

Daly, K.M. (2009). New Mode of Cinema: How Digital Technologies are Changing Aesthetics and Style. Kinephanos, 1 (1). http://www.kinephanos.ca/2009/new-mode-of-cinema-how-digitaltechnologies-are-changing-aesthetics-and-style/

Doane, M.A. (2012). La emergencia del tiempo cinemático: la modernidad, la contingencia y el archivo. Murcia: CENDEAC.

Eco, U. (1977). Tratado de semiótica general, Barcelona: Editorial Lumen.

Esqueda, L. \& Cuevas, E. (2012). Entre la huella y el índice: relecturas contemporáneas de André Bazin. Área Abierta, 33. DOI: http://dx.doi.org/10.5209/rev_ARAB.2012.v33.40557

Giralt, G.F. (2017). The Interchangeability of VFX and Live Action and Its Implications for Realism, Journal of Film and Video, 1 (69), 3-17. DOI: http://www.jstor.org/stable/10.5406/jfilmvideo.69.1.0003

Gunning, T. (2004). What's the Point of an Index? Or, Faking Photographs. Nordicom Review, $\quad 1-2 \quad 39-49$. http://www.nordicom.gu.se/en/tidskrifter/nordicom-review-122004/whats-point-index-or-faking-photographs

Hume, D. (1975). A Treatise of Human Nature, L. A. Selby-Bigge (ed.), Oxford: Clarendon Press. 
Jenna, N. (2007). Virtual Cinematography and the Digital Real: (Dis)placing the Moving Image Between Reality and Simulacra. En D. Sutton, S. Brind \& R. Mckenzie (eds.), The State of the Real: Aesthetics in the Digital Age, (pp.172-180). Londres: Taurus.

Manovich, L. (2005). El lenguaje de los nuevos medios de comunicación. Barcelona: Paidós.

Manovich, L. (1995). What is Digital Cinema?. [09/01/17]. Recuperado de <http://manovich.net/content/o4-projects/oo9-what-is-digitalcinema/o7_article_1995.pdf>

Morgan, D. (2006). Rethinking Bazin: Ontology and Realist Aesthetics. Critical Inquiry, 32, 443-481. DOI: https://doi.org/10.1086/505375

Quintana, À. (2011). Después del cine: imagen y realidad en la era digital. Barcelona: Acantilado.

Rodowick, D.N. (2007). The Virtual Life of Film. Massachusetts: Harvard University Press.

Rosen, P. (2001). Old and New: Image, Indexicality, and Historicity in the Digital Utopia. En P. Rosen, Change Mummified: Cinema, Historicity, Theory (pp. 301-350). Minneapolis: University of Minnesota Press.

Sargeant, Alexi, (2017). The Undeath of Cinema. The New Atlantis, 53, p. 17-32. [03/01/18]. Recuperado de https://www.thenewatlantis.com/publications/the-undeath-of-cinema

Sartre, J-P. (2006). La imaginación. C. Dragonetti (trad.). Buenos Aires: Edhasa.

Seung-Hoon, J. (2016). Multiple Indexicality and Multiple Realism. En I. Aitken (ed.), The Major Realist Film Theories: A Critical Anthology (pp. 94109). Edimburgo: Edinburgh University Press.

Smith, D. (2013). Introduction: Revisiting André Bazin. Paragraph (número especial: revisiting Bazin), 1 (36), 1-2. $\quad$ DOI: https://doi.org/10.3366/para.2013.0074

Torregrosa, M. (2010). La imagen sintética ante el debate representación/simulación. En M. Torregrosa (ed.), Imaginar la realidad: Ensayos sobre la representación de la realidad en el cine, la televisión y los nuevos medios (pp. 23-36). Zamora: Comunicación Social Ediciones y Publicaciones.

\section{Películas citadas}

Bresson, R. (1951). Journal d'un curé de campagne. Francia: UGC.

Cameron, J. (2009). Avatar. Estados Unidos: 20th Century Fox. 
Cuarón, A. (2013). Gravity. Estados Unidos: Warner Bros., Esperanto Filmoj, Heyday Films.

Deren, M. (1943). Meshes of the Afternoon. Estados Unidos: Maya Deren Experimental Films.

Edwards, G. (2016). Rogue One: A Star Wars Story. Estados Unidos: Lucasfilm.

González Iñárritu, A. (2015). The Revenant. Estados Unidos: Regency Enterprises, RatPac-Dune Entertainment, Anonymous Content, M Productions, Appian Way.

González Iñárritu, A. (2014). Birdman or (The Unexpected Virtue of Ignorance). Estados Unidos: Regency Enterprises, New Regency Pictures, M Productions, Le Grisbi Productions, TSG Entertainment, Worldview Entertainment.

Jackson, P. (2002). The Lord of the Rings: The Two Towers. Alemania /Nueva Zelanda/ Estados Unidos: WingNut Films, The Saul Zaentz Company.

Jarmusch, J. (2016). Paterson. Estados Unidos: Amazon Studios, Animal Kingdom, K5 Film.

Jia, Z. (2004). Shijie. China: Office Kitano, Lumen Films, XStream Pictures, Bandai Visual Company, Bitters End, Dentsu, Shanghai Film Group, TV Asahi, Tokyo FM Broadcasting Co., Xinghui Production.

Johnson, R. (2017). Star Wars: The Last Jedi. Estados Unidos: Lucasfilm, Bad Robot.

Lowery, D. (2016). Pete’s Dragon. Estados Unidos: Walt Disney Pictures.

Nolan, Ch. (2010). Inception. Estados Unidos y Reino Unido: Warner Bros., Legendary Entertainment, Syncopy

Sharpsteen, B. (1941). Dumbo. Estados Unidos: Walt Disney Pictures. 